\title{
Assessing Knowledge and Perceptions of Health Care Workers toward Novel Coronavirus (COVID-19)
}

\author{
Hashim Jebur Abed AL-Kaabi ${ }^{1}$, Hussein Ali Mohammed ${ }^{2}$, AbidSalih Kumait ${ }^{3}$ \\ ${ }^{1}$ Ph.D. Adult Nursing, Ministry of Health, ${ }^{2}$ Lecturer Department of Adult Nursing, College of Nursing, University \\ of Kirkuk, ${ }^{3}$ Ph.D. Assistant Professor, Department of Adult Nursing, College of Nursing, University of Kirkuk
}

\begin{abstract}
Objective: To assess the knowledge and perceptions of health care workers towards coronavirus (COVID-19) in most of the governorates of Iraq.

Method: A cross-sectional survey, web-based study was conducted among HCWs about COVID- 19 during the last two weeks of April 2020. Knowledge and Perception were assessed by five components adapted from the Ebola knowledge scale, and A 7-item instrument this part was developed using WHO course materials on Emerging respiratory for viruses COVID-19 and distributed randomly to HCWs using social media. Descriptive statistics were used to express participants' demographic information, mean knowledge score and mean Perception score of HCWs. Chi squares tests were used to assess the association between study variables and Perception questions was used to identify the level of association among variables at the significance level of $\mathrm{p}<0.05$.
\end{abstract}

Result: (184) participated of HCWs complete the survey (64.1\%) are males, aged 20-29 years (54.3\%), and most of them are Nurse (64.7\%) and Lab-technicians (20.1\%). Regarding COVID-19, most of them used social media to obtain the information (68\%), About less than half of the respondents $(41.30 \%)$ opined that COVID-19 was - a severe illness transmitted to people from wild animals. Approximately $87 \%$ of respondents identified "contact by airborne droplets through breathing, sneezing or coughing" as the most common mode of transportation; Most of the participants associated COVID-19 with fever $(90.80 \%)$, shortness of breath $(89.10 \%)$ and coughing (76.66\%). Handwashing and social distraction were chosen by most respondents $(95.70 \%)$ as a method of preventing infection while $9.80 \%$ reported consuming gin, garlic, ginger, herbal mixtures and foods/soups as precautions against COVID-19. The majority of participants $(81 \%)$ believed that COVID-19 is fatal; It was also noted that the social media (Whatsapp, Facebook, Instagram, Twitter etc.) are the most common source of health information about COVID-19 (65.20\%). demonstrated a positive perception of prevention and control towards COVID-19. Most elements of Perception were significantly associated with gender and age at $(\mathrm{P}<0.05)$.

Conclusions: The results of this study showed that healthcare workers have a good knowledge and positive Perception towards COVID-19. As the global threat of COVID-19 continues to emerge, it is critical to additional education interventions and campaigns are required for healthcare workers.

Keywords: Coronavirus, outbreak, COVID-19, Media, knowledge, perceptions, healthcare.

\section{Introduction}

Covids are a huge gathering of infections regular all through society. Truly, proof has demonstrated that the infection is sent by feathered creatures and warm blooded animals, with people especially defenseless against disease and transmission of the infection ${ }^{(1)}$. Past episodes of Covids, for example, SARS-CoV and Middle East Respiratory Syndrome-(MERS-CoV) in 2003 and 2015 show similitudes with the new Covid, which was first detailed in December 2019, which is the momentum sickness in questions Which Caused Coronavirus Outbreak Worldwide, COVID-19. ${ }^{(2)}$ It was first revealed 
by the Chinese experts in Wuhan, capital of Hubei Province in China toward the finish of December $2019^{(3)}$. The progressing COVID-19 pandemic was affirmed without precedent for Iraq in February 2020. Cases were affirmed in each of the nineteen Iraqi governorates until March 27, with the Kurdistan Region of Iraq representing 309 (26\%) of these cases until April 8. ${ }^{(4)}$ During the pandemic, Iraq announced its initially affirmed instances of SARS CoV-2 contamination on February 22, 2020 in Najaf. ${ }^{(5)}$ By April, the quantity of affirmed cases surpassed 100 in Baghdad, Basra, Sulaymaniyah, Erbil, and Najaf. ${ }^{(6)}$ Coronavirus fundamentally spreads from individual to individual through close contact (around 6 feet) with contaminated individuals through the respiratory framework (hacking or wheezing) or is sent by contacting a surface or something in which the infection is discovered ${ }^{(7)}$. As far as manifestations, the World Health Organization revealed that over $80 \%$ of the COVID-19 patients demonstrated gentle indications and recouped with no clinical intercession, and about $20 \%$ of the influenced cases experienced serious sicknesses, for example, dyspnea, septic stun and various organ disappointments. It has been accounted for that $2 \%$ of cases can be deadly ${ }^{(8)}$. furthermore, it is analyzed through a research facility test. Contamination can prompt intense respiratory issues or demise, particularly among the older and individuals with fundamental ceaseless ailments. Notwithstanding, some tainted individuals are transporters of the infection without side effects, while just others may experience the ill effects of a mellow disease and recuperate effectively ${ }^{(9)}$. As of now, there is no particular antiviral therapy and preventive antibody; Medical therapies are restricted to steady measures pointed toward mitigating side effects and the utilization of examination medications and corrective meds. Along these lines, applying a preventive measure to control COVID-19 contamination is a significant intercession. This is finished by washing hands with cleanser and water, by face covers, and confining affirmed and suspected cases (10.11). Furthermore, medical services laborers (HCWs) are at a high danger of contamination and the wellspring of transmission in the network. Some past investigations have demonstrated that HCW laborers need information and Perception about MERS $\mathrm{CoV}^{(12)}$, and SARS ${ }^{(13)}$. Before the finish of January, WHO and CDC (Centers for Disease Control and Prevention) proposals for the avoidance and control of COVID-19 for medical services specialist ${ }^{(14,15)}$. Indeed, WHO has likewise left on various internet instructional classes and articles on COVID-19 unique dialects to advance preventive systems, including mindfulness raising, and preparing arrangement exercises in HCWs (16). This investigation planned to survey information and ideas towards COVID-19 among medical services laborers during this worldwide wellbeing emergency. Additionally, we likewise investigated the function of various data sources in molding the information and impression of COVID-19 HCWs during this pinnacle period.

\section{Method}

1. Setting and Participants: This cross-sectional survey has been carried out to assessing knowledge and perceptions of health care workers toward Novel Coronavirus (COVID-19). They were used an online questionnaire to collect data from participants. health care workers were purposively sent the link through Social media (Whatsapp, Facebook, Telegram, and Fiber) they were asked to participate in an online survey. A snowball sampling technique was conducted using a survey instrument to obtain responses from HCWs from the provinces of Iraq during the last two weeks of April 2020.

2. Procedure: Because of social distance rules and curfews/closures, physical interaction was not possible, so online surveys were promoted and current study participants were urged to send the survey link to potential responders.

\section{Instruments (the questionnaire was divided into}

3 parts): The first part comprised of Social and demographic data were obtained from respondents about variables such as gender, age, marital status, Occupation, and awareness which including heard about Novel coronavirus, and attended lectures/ discussions related to COVID-19.

The second part identified of respondents' Knowledge about Novel Coronavirus COVID-19 was assessed by five components adapted from the Ebola knowledge scale developed by Rolison and Hanoch ${ }^{(17)}$.

Knowledge components of Novel Coronavirus COVID-19 included the method of preventing and curbing the infection, symptoms, source of Novel COVID-19, modes of transmission, perception of Novel COVID-19 fatality and sources of information about Novel COVID-19.

Respondents' knowledge about Coronavirus COVID-19 is accessed by summarizing the correct 
responses via Element 1, method of preventing and curbing the infection, (correct $=(b)$ and (d), (f) or (h)), Element 2, symptoms, (correct = (a), (b) and (g)), Element 3, source of Coronavirus COVID-19, (correct $=(d)$ ), Element 4, transmission of COVID-19, (correct $=(\mathrm{a})$, and (b), (c) or (d)), and Element 5, awareness of Coronavirus COVID-19 fatality, $($ correct $=(a)$ ), the maximum degree possible the generation of five elements. The rule is set to 3 which indicates a moderate level of knowledge about COVID-19. Scores greater than 3 indicated a high level of knowledge about COVID-19 while Scores less than 3 indicated a low level of knowledge about COVID-19. The mean score and the standard deviation for the sample population were calculated to indicate the level of knowledge of the sample. Similarly, scores above the base indicate high knowledge and score lower the base indicated low knowledge of Coronavirus COVID-19 for the sample.

The third part Which consists of Source of Knowledge about Novel coronavirus (4 element/4point Likert scale), and perceptions toward COVID-19 (7 items/Yes or No option), This part was developed using WHO course materials on Emerging respiratory for viruses COVID-19 (World Health Organization. ${ }^{(18)}$.

4. Statistical Analysis: Descriptive statistics were applied to calculate frequencies and percentages of sociodemographic data and knowledge about COVID-19, the Chi-square test was used to explore the level of correlation between variables, Considered the p-value less than 0.05 statistically significant and performed using SPSS Statistic version 19.

\section{Results}

We received responses from 184 HCWs participated, as at 2th May, 2020, which was the data cutoff collection date for this study who had completed the online questionnaires, including the respondents were aged between 20 to $60 \geq$ years old (Mean 26.85, $\mathrm{SD}=9.17)$, and almost all respondents $(\mathrm{n}=118,64.1$ $\%)$ are male, Regarding to marital status $(58.7 \%)$ were married. Majority of respondents are Nurse $(n=119$, 64.7\%), and Lab-technicians ( $\mathrm{n}=37,20.1 \%)$, and almost all respondents agreed that they heard about Novel Coronavirus (COVID-19) ( $\mathrm{n}=183,99.5 \%)$, but only ( $\mathrm{n}=124,67.4 \%)$, of them got the chance to attend lectures/discussions about Novel Coronavirus (COVID-19) Table (1).
Table (1) Sociodemographic characteristics of Healthcare workers' $(\mathrm{N}=184)$.

\begin{tabular}{|c|c|c|c|}
\hline \multirow{2}{*}{ Variables } & \multirow{2}{*}{ Groups } & \multicolumn{2}{|c|}{ Case } \\
\hline & & $\mathbf{F}$ & $\%$ \\
\hline \multirow{7}{*}{ Age groups } & $\begin{array}{l}\text { Less than } 20 \\
\text { year }\end{array}$ & 2 & 1.1 \\
\hline & $20-29$ & 100 & 54.3 \\
\hline & $30-39$ & 62 & 33.7 \\
\hline & $40-49$ & 15 & 8.2 \\
\hline & $50-59$ & 4 & 2.2 \\
\hline & $60 \geq$ & 1 & 0.5 \\
\hline & $x \pm \mathrm{SD}$ & \multicolumn{2}{|c|}{$26.85 \pm 9.17$} \\
\hline \multirow{2}{*}{ Gender } & Male & 118 & 64.1 \\
\hline & Female & 66 & 35.9 \\
\hline \multirow{4}{*}{ Marital status } & Single & 74 & 40.2 \\
\hline & Married & 108 & 58.7 \\
\hline & Divorced & 1 & 0.5 \\
\hline & Widow & 1 & 0.5 \\
\hline \multirow{7}{*}{ Occupation } & Doctors & 2 & 1.1 \\
\hline & Dentist & 2 & 1.1 \\
\hline & Pharmacists & 5 & 2.7 \\
\hline & Nurse & 119 & 64.7 \\
\hline & Lab-technicians & 37 & 20.1 \\
\hline & Administrative & 2 & 1.1 \\
\hline & $\begin{array}{l}\text { Other } \\
\text { occupations }\end{array}$ & 17 & 9.2 \\
\hline \multirow{2}{*}{$\begin{array}{l}\text { Heard about Novel } \\
\text { coronavirus }\end{array}$} & Yes & 183 & 99.5 \\
\hline & No & 1 & 0.5 \\
\hline \multirow{2}{*}{$\begin{array}{l}\text { Attended lectures/discussions } \\
\text { about Novel Coronavirus }\end{array}$} & Yes & 124 & 67.4 \\
\hline & No & 60 & 32.6 \\
\hline
\end{tabular}

$\mathrm{N}=$ number of samples, $\mathrm{F}=$ frequency, $\%=$ percentage, $\bar{x}=$ Mean, $\mathrm{SD}=$ standard deviation.

When we requested about sources of information about COVID-19, it was the main source of information obtained through social media (Facebook, Twitter, Whatsapp, YouTube, Instagram, Snapchat) and official government websites. $36 \%$ of the respondents reported they use news media (TV/video, magazines, newspapers, and radio) to obtain information about COVID-19. Furthermore, over $80 \%$ of respondents sometimes discussed COVID-19 related topics with family and friends (Figure 1). 


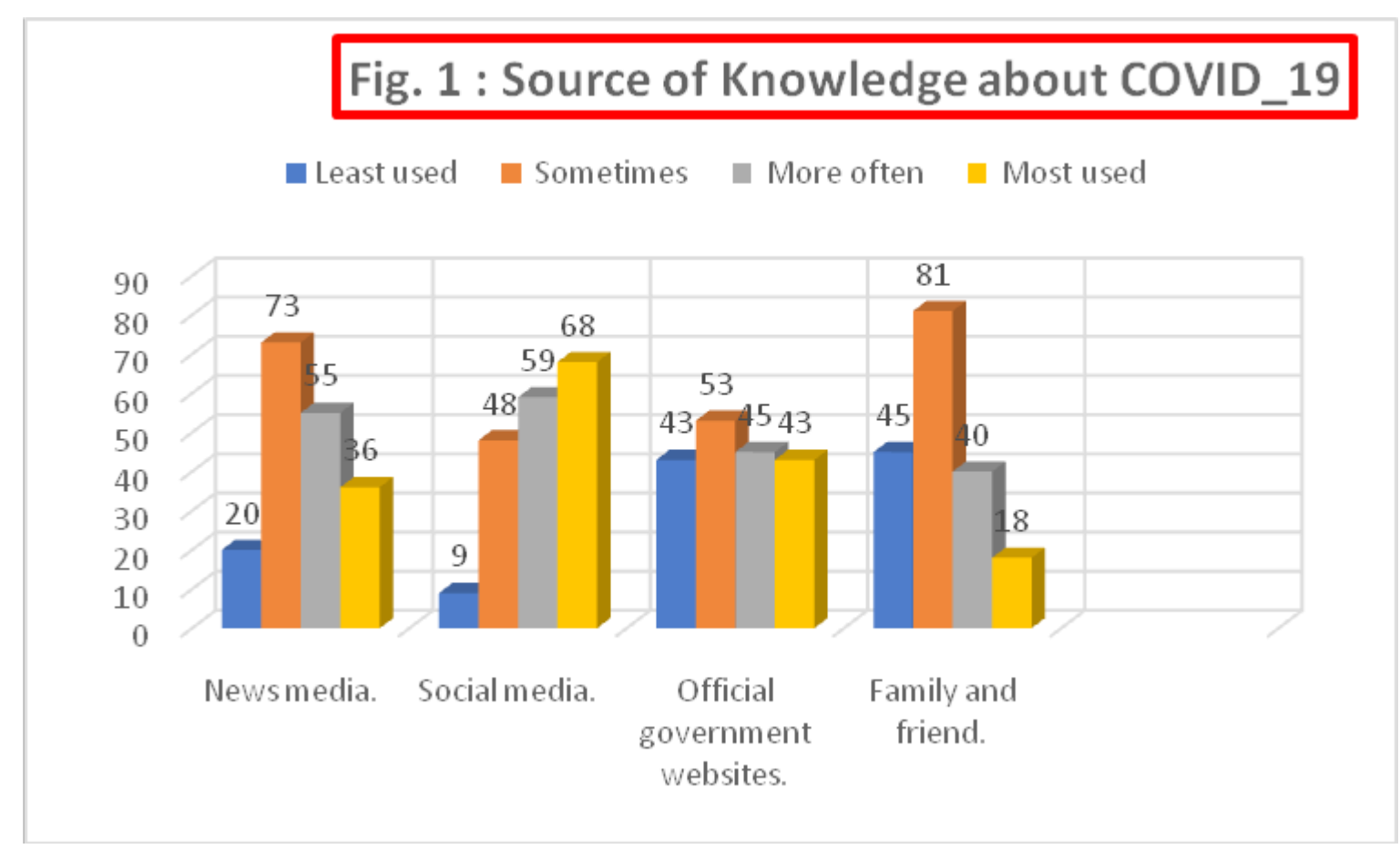

The results (Figure 2) showed that about less than half of the respondents (41.30\%) opined that COVID-19 is - a severe illness transmitted to people from wild animals while $29.90 \%$ identified it as - a biological weapon designed by the government of China.

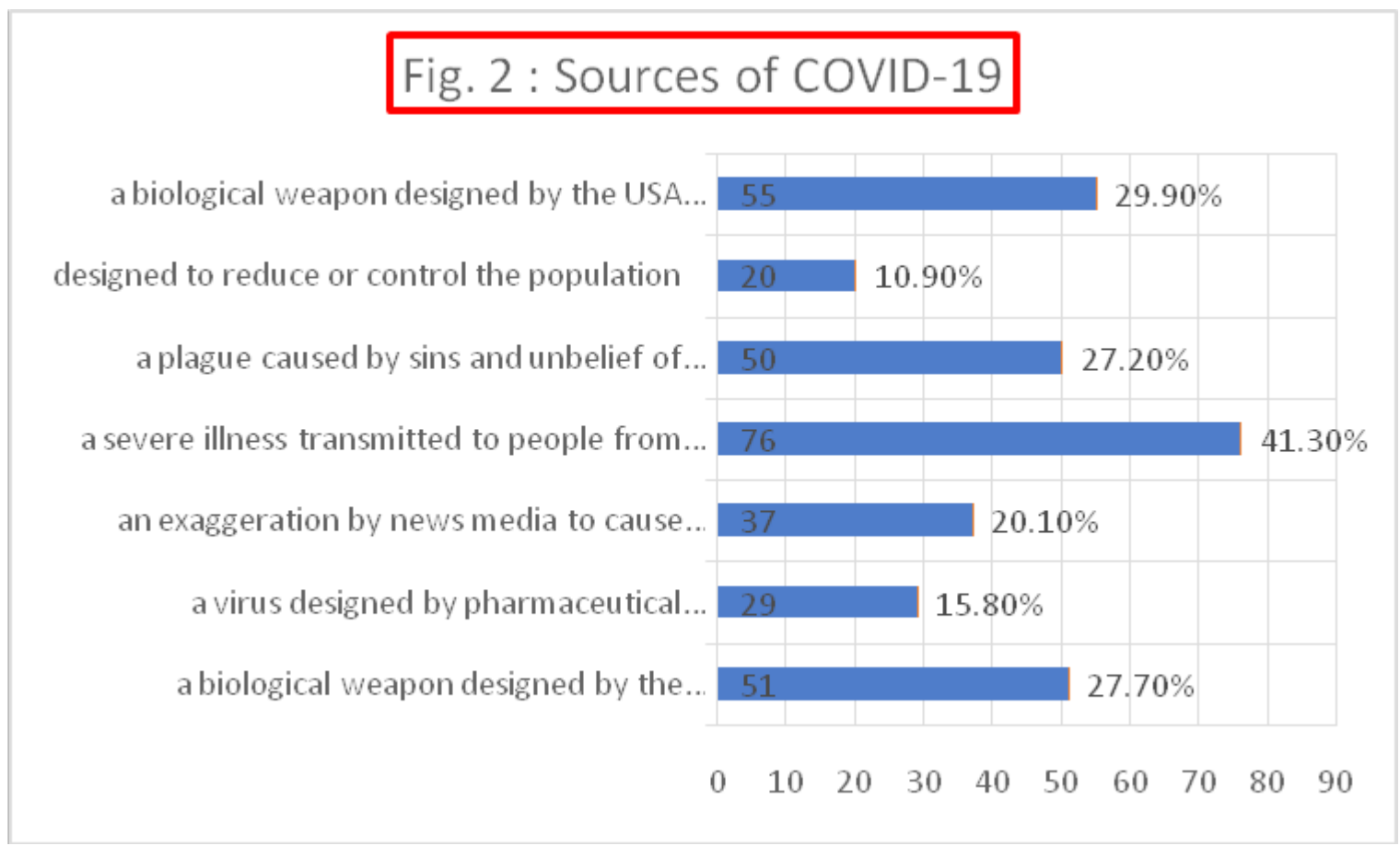

Concerning knowledge about the most common mode of transportation, approximately all (87\%) were chosen to "contact drops from an infected person/object by breathing, sneezing or coughing" while slightly more than the average $(76.60 \%)$ chose "touching contaminated objects" or surfaces. - As a means of transmitting and communicating with the virus (Figure 3). 


\section{Fig. 3: Transmission of COVID-19}

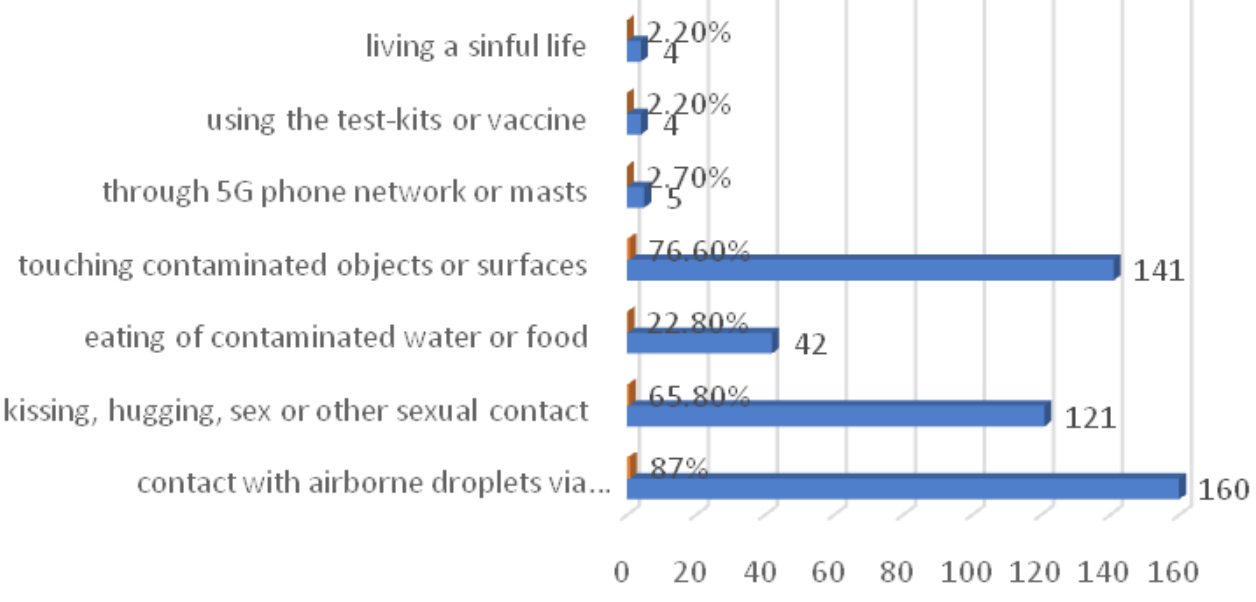

The high majority of the HCWs knew that washing hands with soap and water could help to prevent COVID-19 transmission (99.5\%), and sick patients must share their last travel history (98.9\%), and symptoms will appear in 2-14 days (97.3\%)). Besides, (96.2\%) agreed that all equipment used in wet markets should be

cleaned every day. Feeling unclear eating well-cooked meat during an outbreak of $88.6 \%$ and flu vaccination is not enough to prevent $(88.6 \%)$. However, about $66.8 \%$ of the HCWs knew that were not fatal regarding COVID-19 (Table 2).

Table 2: Perception about COVID-19 among Healthcare workers' (N=184).

\begin{tabular}{|c|c|c|c|c|}
\hline \multirow{2}{*}{ Statements } & \multicolumn{2}{|c|}{ Yes } & \multicolumn{2}{|c|}{ No } \\
\hline & $\mathbf{F}$ & $\%$ & $\mathbf{F}$ & $\%$ \\
\hline COVID-19 symptoms appear in 2-14 days. & 179 & $97.3 *$ & 5 & 2.7 \\
\hline COVID-19 is fatal. & 123 & $66.8^{*}$ & 61 & 33.2 \\
\hline Flu vaccinated is sufficient for preventing COVID- 19. & 21 & 11.4 & 163 & $88.6^{*}$ \\
\hline During the outbreak, eating well-cooked and safely handled meat is safe. & 163 & $88.6^{*}$ & 21 & 11.4 \\
\hline Sick patients should share their recent travel history with healthcare providers. & 182 & $98.9 *$ & 2 & 1.1 \\
\hline Disinfect equipment's and working area in wet markets at least once a day. & 177 & $96.2 *$ & 7 & 3.8 \\
\hline Washing hands with soap and water can help in prevention of COVID-19 transmission & 183 & $99.5^{*}$ & 1 & 0.5 \\
\hline
\end{tabular}

$\mathrm{N}=$ number of samples, $\mathrm{F}=$ frequency, $\%=$ percentage, $*$ correct answers.

The elements of perception COVID-19 among HCWs in the study were analyzed using a test $\chi^{2}$ to evaluate the correlation with age, sex. (Table 4).

\section{Discussion}

Presently, COVID-19 is the subject of worldwide discussion in the media and among people in general, particularly among HCWs and patients. With the current increment in COVID-19 transmission that has raised pressures for everybody, including wellbeing and wellbeing framework authorities, this is an issue of how data is figured out how to help forefront laborers in general wellbeing emergency circumstances. Thus, this information and view of medical care experts can help contain the plague by forestalling and controlling COVID-19 during a worldwide scourge, which will 
improve the physical and psychological well-being of people.

The aftereffects of this investigation demonstrated that a huge level of study members knew about and proficient about COVID-19. The outcomes were related with information on COVID-19 as far as respondents' information on the wellspring ofCOVID-19, transmission of COVID-19, manifestations of COVID-19, preventive conduct towards COVID-19, mortality from COVID-19 and the primary wellsprings of data about COVID-19 for medical services laborers, the outcomes were altogether high.

The a large portion of HCWs (68\%) utilized web-based media as a significant wellspring of data, additionally around $43 \%$ that pertinent COVID-19 updates posted online by legitimate government wellbeing specialists have indicated that they effectsly affect improving the information levels of HCWs. Furthermore, hence, rely upon solid sources is a primary factor in accepting that straightforward data about a COVID-19 disease is essential for react to HCWs. These days, an assortment of data accessible on the web and this unsubstantiated data can spread rapidly and can misdirect medical care laborers. Wellbeing specialists and specialists specifically have cautioned against the inescapable falsehood of COVID-19 ${ }^{(19,20-12)}$. In this regard, medical care laborers should practice cautious assessment of the data identified with COVID-19, and the first and logical substance of the data sources ought to be utilized. The aftereffects of the current investigation likewise firmly uphold comparable outcomes in which the fundamental wellspring of MERS was accounted for as the web and web-based media ${ }^{(22,23)}$ (Figure 1).

The outcomes (Figure 2) indicated that about not exactly $50 \%$ of the respondents $(41.30 \%)$ thought that COVID-19 is - an extreme sickness communicated to individuals from wild creatures. This is apparent of the different wellsprings of data concerning the COVID-19 that is accessible ${ }^{(24)}$.

Most of respondents (87\%) were about the transmission of COVID-19 through airborne drops by means of breathing, wheezing, or hacking which is like an examination by Li, Weic, et al. ${ }^{(25)}$. (Figure 3 ).

The outcomes appeared, true to form, that medical services experts have a generally high information on COVID-19, and a decent extent concur that a lot of practices endorsed and affirmed by the World Health
Organization, for example, hand washing, physical separating, surface sanitization Contaminated, school closings and public occasions, and vaporization of spots the public was important to forestall the spread of the infection. Just a couple of consented to depend on blessing oil, supplication, blistering climate and the utilization of qualities, spices and nourishments, just as chloroquine and anti-infection agents as precautionary measures for the spread of the pandemic. These outcomes are predictable with the past examination Bhagavathula et al. ${ }^{(26)}$. In one examination, it was discovered that medical services laborers washing hands were higher among attendants than different specialists (27). Likewise, the most ideal approach to forestall transmission is by washing hands and utilizing social removing, sterilization of tainted surfaces. Our outcomes are like those of the Khan concentrate on Middle East respiratory disorder ${ }^{(28)}$.

When all is said in done, contrasts were distinguished across various classes of HCWs in their recognitions. About $87.9 \%$ of wellbeing laborers somewhere in the range of 20 and 29 years of age understood that flu antibody was deficient to forestall COVID-19 at (p esteem 0.009) and More than $90 \%$ of a similar age gathering (20-29) understood that eating meat during an episode is sheltered at (p esteem 0.02). (99\%) of HCWs decidedly accept that announcing the ongoing travel history when people are wiped out at (p esteem 0.004), and they understand that indications of COVID-19 show up between 2 to 14 days. At last, most of medical services laborers unequivocally consent to keep up handwashing with cleanser that can help forestall COVID-19 transmission (at $p$ esteem 0.045) and tidy up hardware utilized in wet business sectors .

\section{Conclusions}

The current examination is a study to survey information and discernments about COVID-19 among medical care laborers. This examination was significant in light of the fact that it considered information about COVID-19 in the majority of the governorates of Iraq. spaces of information incorporate source, transmission, side effects, wellsprings of data, and defensive conduct toward COVID-19. The outcomes affirm that medical care laborers are completely mindful of COVID-19 and their fundamental wellsprings of data about the pandemic are customary media. As the worldwide danger of COVID-19 keeps on developing, there is a pressing need to convey wellbeing instruction crusades generally 
to medical care laborers to expand the knowledge of healthcare workers that will positively influence their perceptions towards COVID-19.

Financial Disclosure: There is no financial disclosure.

Conflict of Interest: None to declare.

Ethical Clearance: All experimental protocols were approved under the Department of Adult Nursing and all experiments were carried out in accordance with approved guidelines.

\section{References}

1. Schoeman D, Fielding BC. Coronavirus envelope protein: Current knowledge. Virol J 2019; 16(1): 69.

2. WHO. Coronavirus disease 2019 (COVID-19): World Health Organization. 2020.

3. Carlos WG, Dela Cruz CS, Cao B, Pasnick S, Jamil S. Novel Wuhan (2019-nCoV) Coronavirus. Am J RespirCrit Care Med 2020; 201(4): 7-8.

4. Jump up to:a b c d "Covid-19 situation update in Iraqi Kurdistan". gov.krd/coronavirus-en.

5. Iraq announces 1st case of COVID-19 in Najaf World - Chinadaily.com.cn". www.chinadaily. com.cn.

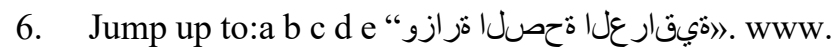
facebook.com. Retrieved 31 March 2020.

7. CDC. Coronavirus disease 2019 (COVID-19). 2020. [Online]. Available from: https://www.cdc. gov/coronavirus/2019-ncov/about/transmission. html [Accessed on 1st March 2020].

8. WHO. WHO Director-General's opening remarks at the mission briefing on COVID-19. 2020. [Online]. Available from: https://www.who.int/dg/speeches/ detail/who-director-general-s-opening-remarks-atthe-mission-briefing-on-covid-19 [Accessed on 1st March 2020].

9. Sauer, L. M. (2020). What Is Coronavirus? Available online at https://www.hopkinsmedicine. org/health/conditions-and-diseases/coronavirus

10. CDC. Coronavirus disease 2019 (COVID-19). 2020. [Online]. Available from: https://www.cdc. gov/coronavirus/2019-ncov/about/transmission. html [Accessed on 1st March 2020].

11. WHO. WHO Director-General's opening remarks at the mission briefing on COVID-19. 2020. [Online].
Available from: https://www.who.int/dg/speeches/ detail/who-director-general-s-opening-remarks-atthe-mission-briefing-on-covid-19 [Accessed on 1st March 2020].

12. Abdullah A, Allen C. Knowledge, attitudes and behaviours of healthcare workers in the Kingdom of Saudi Arabia to MERS coronavirus and other emerging infectious diseases. Int J Environ Res Public Health 2016; 13: 1214.

13. Deng JF, Olowokure B, Kaydos-Daniels SC, Chang HJ, Barwick RS, Lee ML, et al. Severe acute respiratory syndrome (SARS): Knowledge, attitudes, practices and sources of information among physicians answering a SARS fever hotline service. Public Health 2006; 120(1): 15-19.

14. World Health Organization. Infection prevention and control during health care whennovel coronavirus (nCoV) infection is suspected: interim guidance, January 2020. WorldHealth Organization; 2020.

15. Centers for disease control and prevention. Update and interim guidelines on outbreak of 2019 Novel coronavirus (2019-nCoV).

16. World health organization. Responding to COVID-19: Real-time training for thecoronavirus disease outbreak. 2020.

17. Rolison, J. J. \& Hanoch, Y. (2015). Knowledge and risk perceptions of the Ebola virus in the United States. Preventive Medicine Reports, 2, 262-264.

18. World health organization. Emerging respiratory viruses, including COVID-19: method for detection, prevention, response, and control. Available online: https://openwho.org/courses/introduction-to-ncov (2020).

19. Lai CC, Shih TP, Ko WC, Tang HJ, Hsueh PR. Severe acute respiratory syndrome coronavirus 2 (SARS-CoV-2) and corona virus disease-2019 (COVID-19): the epidemic and the challenges. Int J Antimicrob Agent. 2020:105924. Doi:10.1016/j. ijantimicag.2020.105924.

20. Thomas Z. Misinformation on coronavirus causing 'infodemic'. https://www.bbc.com/news/ technology-51497800 (2020).

21. Mejova Y, Kalimeri K. Advertisers Jump on Coronavirus Bandwagon: Politics, News, and Business. arXiv preprint arXiv 2020:2003.00923.

22. Nour MO, Babilghith AO, Natto HA, Al-amin FO, Alawneh SM. Knowledge, atti-tude and practices 
of healthcare providers towards MERS-CoV infectionatMakkah hospitals. KSA 2015;3:103-12.

23. Khan MU, Shah S, Ahmad A, Fatokun O. Knowledge and attitude of healthcareworkers about middle east respiratory syndrome in multispecialty hospitals ofqassim, Saudi Arabia. BMC Public Health 2014;14:1281.

24. Hassan, I. (March 26, 2020). The other COVID-19 pandemic: Fake news.

25. Li, W., Zhang, B., Lu, J., Liu, S., Chang, Z., Cao, P., Liu, X., Zhang, P., Ling, Y., Tao, K. and Chen, J., 2020. The characteristics of household transmission of COVID-19. Clinical Infectious Diseases.

26. Bhagavathula, Akshaya Srikanth, et al. "Novel Coronavirus (COVID-19) Knowledge and Perceptions: A Survey on Healthcare workers." medRxiv (2020).

27. Joshi S, Joshi A, Park BJ, Aryal UR. Hand washing practice among health careworkers in a teaching hospital. J Nepal Health Res Counc 2013;23:1-5.

28. Khan MU, Shah S, Ahmad A, Fatokun O. Knowledge and attitude of healthcare workers about Middle East Respiratory Syndrome in multispecialty hospitals of Qassim, Saudi Arabia. BMC Public Health 2014; 14: 1281.
29. Mungroo, M.R., Khan, N.A. and Siddiqui, R., 2020. Novel Coronavirus: current understanding of clinical features, diagnosis, pathogenesis, and treatment options. Pathogens, 9(4), p.297.

30. Lau, J. T. F., Yang, X., Tsui, H., \& Kim, J. H. (2003). Monitoring community responses to the SARS epidemic in Hong Kong: from day 10 to day 62. J EpidemiolCommun Health, 57:864-70.

31. Tice $\mathrm{AD}$, Kishimoto $\mathrm{M}$, Dinh $\mathrm{CH}$, Lam GT, Marineau M. Knowledge of severe acute respiratory syndrome among community physicians, nurses, and emergency medical responders. Prehosp Disaster Med 2006; 21(3): 183-189.

32. Worldometers (April 9, 2020). Coronavirus Update (Live). Available online at https://www. worldometers.info/coronavirus/

33. Mannan, D.K.A. and Mannan, K.A., 2020. Knowledge and perception towards Novel Coronavirus (COVID 19) in Bangladesh. International Research Journal of Business and Social Science, 6(2). 